\begin{abstract}
Currently, there is an interest in effective technologies that cause minimal environmental harm, have low financial costs and allow you to obtain products with high added value. One of the ways to increase the yield of light and medium fractions from oil bottom sediments is to use the electrohydraulic effect. The electrohydraulic phenomenon is a new industrial method of converting electrical energy into mechanical energy, which occurs without the influence of intermediate mechanical links, with high efficiency. Statistical processing of experimental data was carried out with the identification of the optimal mode of the electrohydraulic effect on the destruction of the oil bottom sediment. The influence of various factors is shown (duration of contact, distance between electrodes, amount of added catalyst, capacitance of capacitor and value of applied voltage). The use of the generalized equation made it possible to determine the following optimal conditions for the destruction of the oil bottom sediment using electrohydraulic treatment: duration $7 \mathrm{~min}$, distance $8 \mathrm{~mm}$, amount of added catalyst $1.5 \%$, capacitance $0.3 \mu \mathrm{F}$, applied voltage $14 \mathrm{kV}$. In terms of the significance of the coefficient (tr), it should be noted that the dominant factors are the distance between the electrodes and the amount of added catalyst. The individual chemical composition of the light and medium fractions of the original oil residue and the processed oil residue was determined. Comparison of the individual chemical composition of fractions up to $200{ }^{\circ} \mathrm{C}$ and 200 $300{ }^{\circ} \mathrm{C}$, obtained from the oil bottom sediment and from the hydrogenated product, allowes to conclude that the electrohydraulic effect has an effective effect on the destruction of the organic mass of the oil bottom sediment. The optimal conditions for electrohydraulic treatment of the oil residue aere established and it is shown that it is possible to utilize the oil bottom sediments

Keywords: electrohydraulic phenomenon, catalyst, oil bottom sediment, viscosity, density, optimization, hydrogenation
\end{abstract}

UDC 665.666.002.8

DOI: $10.15587 / 1729-4061.2021 .241763$

\title{
DETERMINATION OF OPTIMAL CONDITIONS FOR PROCESSING OIL BOTTOM SEDIMENTS USING ELECTROHYDRAULIC EFFECT
}

Amangeldy Satybaldin Corresponding author

PhD, Associate Professor*

E-mail: Satybaldin.1975@mail.ru

A Imas Tusipkhan

PhD Doctor, Associate Professor**

Raikhan Seitzhan

Master of Engineering Sciences**

S a i r a u I Tyanak h

$\mathrm{PhD}$, Doctoral Student

Department of Physical and Analytical Chemistry***

Gulzhan Baikenova

Doctor of Chemical Sciences, Professor, Head of Department

Department of Ecology and Assessment

Karaganda Economic University of Kazpotrebsoyuz Akademicheskaya str., 9, Karaganda,

Republic of Kazakhstan, 100009

Da n a Ka r bekova

PhD, Associate Professor*

Murzabek Baikenov

Doctor of Chemical Sciences, Professor, Head of Department** *Department of Engineering Thermophysics named after Professor Zh. S. Akylbayev*** **Department of Chemical Technology and Petrochemistry*** ***Karaganda Buketov University University str., 28, Karaganda, Republic of Kazakhstan, 100024
Received date 10.09.2021 Accepted date 18.10.2021 Published date 29.10.2021
How to Cite: Satybaldin, A., Tusipkhan, A., Seitzhan, R., Tyanakh, S., Baykenova, G., Karabekova, D., Baykenov, M. (2021). Determination of optimal conditions for processing oil bottom sediments using electrohydraulic effect. Eastern-European Journal of Enterprise Technologies, 5 (6 (113)), 30-38. doi: https://doi.org/10.15587/1729-4061.2021.241763

\section{Introduction}

In the first middle of the XX century, it was found that when a specially formed pulsed high-voltage electric discharge is created inside the liquid volume, high pressures grow in the region of the latter, which can be used in practice. The method of converting electrical energy into mechanical energy is called the electrohydraulic phenomenon [1].

The electrohydraulic phenomenon is a new industrial method of converting electrical energy into mechanical energy, which occurs without the influence of intermediate mechanical links, with high efficiency. The base of this method is that when a specially formed pulsed electric (spark, brush and other forms) discharge passes through the volume of a liquid located in an open or closed vessel, around the zone of discharge formation, ultra-high hydraulic pressures are found, which can perform useful mechanical work and are accompanied by a complex of physical and chemical phenomena $[2,3]$.

The intensive development of industry and the expansion of the sphere of oil use increase environmental pollution. As you know, the most dominant factor of environmental damage is the transportation and storage of oil and petroleum products. During transportation and emergency situations, hydrocarbon raw materials can cause great environmental problems due to the ingress of these substances into the soil and aquatic environment. A large amount of oil sludge is stored at oil refineries. As is known, in addition to asphaltenes, resins and paraffins, oil sludge contains a significant amount of oil. There is a need to extract more and more light fractions from oil sludge due to the increasing consumption of light fuels. This solves the problem of environmental protection and increasing the production of light distillates from oil sludge. 


\section{Literature review and problem statement}

As is known, during the operation of oil reservoirs, the problem of deposition of solid particles and heavy paraffinic sediments on the bottom of the reservoir often arises [4]. The fallout of these oil sediments entails a decrease in the useful volume of the reservoir, prevents free mixing of oil layers, which in turn contributes to the concentration of aggressive salt solutions in the bottom area and the development of corrosive destruction of oil reservoirs [5]. It is known [3] that there is no unified method for processing oil sludge. Most of the known physicochemical technologies for processing oil bottom sediments are not universal, but they can give the maximum result when using waste as a raw material for obtaining a useful product $[6,7]$. The modern development of the oil industry will be directed towards the development of waste-free technologies and the reduction of the amount of oil residues and oil bottom sediments.

In the literature [8-11], a set of measures is used to resolve such situations (for example, manual and mechanized cleaning of tanks using hot water, chemicals, biostrains, nutritional supplements and enzymes). However, existing methods do not allow processing bottom oil sludge into low molecular weight organic compounds. The use of the electrohydraulic phenomenon makes it possible to extract gasoline and diesel fuel from oil bottom sediments. The above technologies for the utilization of oil sludge have high capital costs and do not allow for high profits.

Analysis of literature sources [12-14] showed that the electrohydraulic effect is most effective for processing oil sludge. The use of the electrohydraulic phenomenon makes it possible to extract gasoline and diesel fuel from oil bottom sediments with a high yield. However, in the presented literature sources [3,12-15], a high yield of light fractions is achieved by mixing oil sludge with light oil, gasoline and diesel fuel. In addition, these operations are similar to the fact that the pre-prepared mixture in the reactor is heated from 85 to $180{ }^{\circ} \mathrm{C}$. Performing the electrohydraulic effect with the addition of light hydrocarbons to oil sludge can lead to an explosive situation. In the literature, there are no results on the influence of the catalyst on the process of oil sludge processing using the electrohydraulic effect. Due to the complexity of the chemical composition of oil sludge, there is no information in the literature about the possibility of optimal control of the oil sludge processing process. The methods of planning the technological process (experiment) allow you to vary all factors simultaneously and obtain quantitative estimates of the main and interaction effects.

\section{The aim and objectives of the study}

The aim of the work is to develop a technology for complex processing of oil bottom sediments using the electrohydraulic effect with an iron-containing catalyst and obtaining motor fuels and a valuable technical substance.

To achieve the aim, the following objectives were set:

- to determine the optimal conditions for processing oil bottom sediments using the electrohydraulic effect;

- to determine the influence of the electrohydraulic effect in the presence of a catalyst on the change in the group and individual chemical composition of the light and medium oil fractions.

\section{Materials and methods}

Experimental part. An oil bottom sediment formed during the operation of oil reservoirs during the transportation of West Kazakhstan oils of the Republic of Kazakhstan was used as a feedstock. The oil bottom sediment is characterized by high density and viscosity $\left(0.87 \mathrm{~g} / \mathrm{cm}^{3}\right.$ and $\left.30 \mathrm{cSt}\right)$. The oil bottom sediment has the following chemical characteristics: $\mathrm{A}-0.36 \%, \mathrm{C}-72.3 \%, \mathrm{H}-11.1 \%, \mathrm{~S}-0.1 \%, \mathrm{~N}-0.1 \%$, $\mathrm{O}-16.1 \%$. The atomic hydrogen to carbon ratio of the oil bottom sediment is 1.8 .

This method is based on the shock-wave interaction of the electrohydraulic effect on the processed raw materials. When a shock wave passes through a water-oil medium, destruction of the molecular structures of heavy oil sediment is observed, which is reduced to a viscous homogeneous mixture. The general diagram of the reactor and the effect of shock-wave action on the structure of oil bottom sediments is shown in Fig. 1.

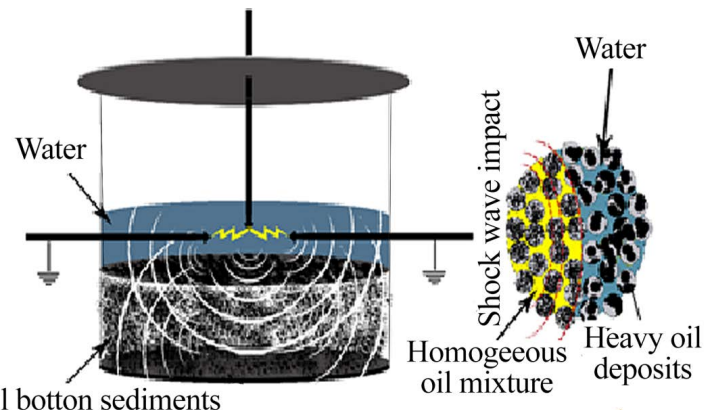

Fig. 1. Diagram of the reactor and the effect of shock-wave impact on the structure of oil bottom sediments

It is known that the electrohydraulic effect initiates many physicochemical processes. As in the process of electrohydraulic processing of oil and oil products, the energy released during the collapse of cavitation bubbles is used for large amounts of water.

The general diagram of the pulse voltage generator and the control panel is shown in Fig. 2.

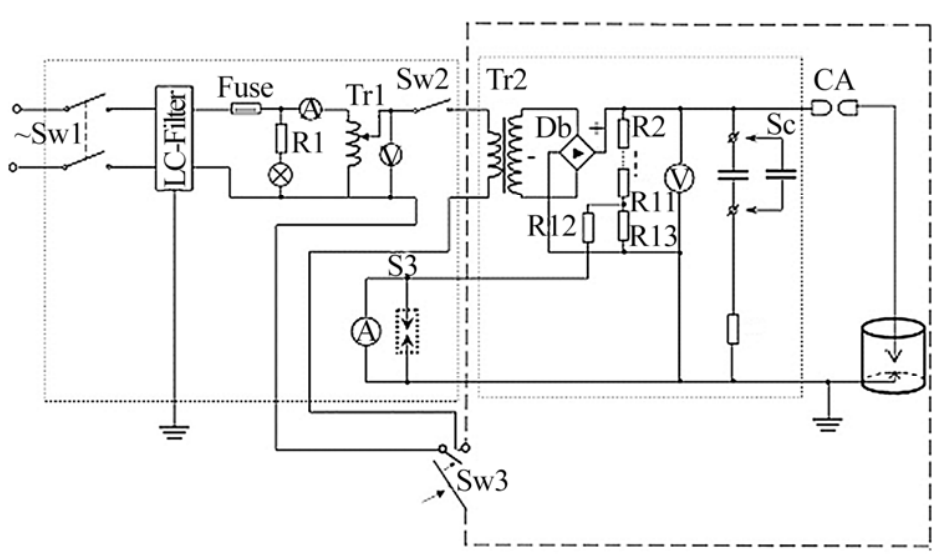

Fig. 2. Basic diagram of the pulse voltage generator and the control panel

The generator unit includes an energy storage unit assembled from a bank of pulse capacitors of an experimental plant (c. Serpukhov). The generator operates in the following sequence: after turning on the power circuit, using the circuit 
breaker Bk1, voltage is supplied through the LC filter to the autotransformer Tp1, through which the voltage for the required operating mode is set. After such a choice, the main element of the generator circuit - the high-voltage transformer Tp2, which generates a voltage in the range from 10 to $50 \mathrm{kV}$, is switched on by the second automatic switch Bk2. After rectification by means of the D1-4 bridge circuit, the voltage goes to charging the storage capacities $\mathrm{C}_{\mathrm{H}}$. The value of the storage capacitance can be regulated in parallel, by connecting in series pulse capacitors of different ratings. The control over the high voltage supply is carried out by a milliammeter using the elements $\mathrm{R} 2-\mathrm{R} 13$, the amplitude value of the voltage is changed by a ball spark gap (special manufacture), and the effective voltage value - by a kilovoltmeter. After a certain period of time equal to the charging time $\mathrm{C}_{\mathrm{H}}$, the capacitor bank will be fully charged, and at this stage the generator is ready to transfer the stored energy to the controlled spark gap and then to the electrodes of the working section.

During the electrohydraulic processing of hydrocarbon raw materials, the destruction of molecules occurs, caused by microcracking of molecules and ionization processes. The volume of the reactor for the electrohydraulic treatment of oil bottom sediments is $300 \mathrm{ml}$. The reactor was charged with $200 \mathrm{~g}$ of oil bottom sediment and $2 \mathrm{~g}$ of the catalyst. The catalyst used was a ferrosphere isolated from the microsphere by magnetic separation of the microsphere. The microsphere was healed from coal ash. Ash was obtained by burning coal at CHPP-3 (thermal power plant in Karaganda). The chemical composition of the ferrosphere mass. \%: $\mathrm{Fe}_{2} \mathrm{O}_{3}-83.4, \mathrm{CaO}-7.6$, $\mathrm{SiO}_{2}-5.7, \mathrm{Al}_{2} \mathrm{O}_{3}-3.2$, the rest is $\mathrm{MgO}, \mathrm{Na}_{2} \mathrm{O}, \mathrm{K}_{2} \mathrm{O}, \mathrm{TiO}_{2}$, $\mathrm{SO}_{3}$. The electrohydraulic shock (EH) ranged from 120 to 480 . The capacity of the catalyst was $0.25-1.0 \mu \mathrm{F}$. The distance between the electrodes is from 5 to $8 \mathrm{~mm}$. Duration 2-8 minutes. Capacitor voltage - from 12 to $18 \mathrm{kV}$.

After processing the oil bottom sediment, the resulting hydrogenated product was fractionated into two fractions: a fraction up to $200{ }^{\circ} \mathrm{C}$ and $200-300{ }^{\circ} \mathrm{C}$. The individual chemical composition of the light and middle fractions was determined using gas chromatography-mass spectrometry on an HP 5890/5972 MSD device from Agilent (USA).

The substances were identified using the NIST98 mass spectral database.

Chromatography conditions:

1) column: DB-5, $30 \mathrm{~m} \times 0.25 \mathrm{~mm} \times 0.5 \mathrm{um}$;

2) gas: helium, $0.8 \mathrm{ml} / \mathrm{min}$;

3) thermostat:

$-50{ }^{\circ} \mathrm{C}-4 \mathrm{~min}$

$-50-150{ }^{\circ} \mathrm{C}-10{ }^{\circ} \mathrm{C} / \mathrm{min}$;

$-150-300^{\circ} \mathrm{C}-20^{\circ} \mathrm{C} / \mathrm{min}$;

$-300{ }^{\circ} \mathrm{C}-4 \mathrm{~min}$;

4) evaporator: $250{ }^{\circ} \mathrm{C}$;

5) evaporator: $200^{\circ} \mathrm{C}$.

\section{Results obtained during the planning of a full factorial experiment of oil sludge processing using the electrohydraulic effect}

5. 1. Determination of the optimal conditions for processing oil bottom sediments using the electrohydraulic effect

The optimal conditions for processing oil bottom sediments using the electrohydraulic effect were determined using the method of mathematical planning of the experiment and static processing of experimental data with the derivation of a gener- alized equation according to Protodyakonov [10]. The experiments were carried out using the matrix presented in Table 1.

The yield of the fraction up to $300{ }^{\circ} \mathrm{C}$ from the hydrogenate was estimated by several functions: the yield of the fraction up to $300{ }^{\circ} \mathrm{C}(Y 1)$ from the duration of the processing of the oil bottom sediment during electrohydraulic processing, the yield of the fraction up to $300{ }^{\circ} \mathrm{C}(Y 2)$ from the distance between the electrodes, the yield of the fraction up to $300{ }^{\circ} \mathrm{C}(Y 3)$ from the capacitor capacitance, the yield of the fraction up to $300{ }^{\circ} \mathrm{C}(Y 4)$ from the amount of added catalyst to the oil bottom sediment, the yield of the fraction up to $300{ }^{\circ} \mathrm{C}(Y 5)$ from the applied voltage, since the optimization of the process using several partial equations is more detailed and accurate.

After carrying out matrix experiments, sampling at the level and selection of partial dependencies by the method of successive approximation were carried out. Initially, the experimental data were approximated by the equation of a straight line. Moreover, if the model turned out to be adequate (with significant correlation coefficients), then it was preserved, in case of inadequacy, they switched to higher-order models. Also, information related to the physical meaning of the studied dependence was used. Variable factors and levels of their variation are shown in Table 2. Dot plots and curves of approximation to optimize the process of the impact of electrohydraulic shock on the destruction of the oil bottom sediment are shown in Fig. 2.

Each of the partial functions (Table 3) was checked for significance using the coefficient of nonlinear multiple correlation $(R)$

$$
R=\sqrt{1-\frac{(N-1) \sum_{1}^{n}\left(\left(Y \exp -Y_{p}\right)\right)^{2}}{(N-K-1) \sum_{1}^{n}\left(\left(Y \exp -Y_{\text {mid }}\right)\right)^{2}}}>0.66,
$$

and its significance for the $5 \%$ level

$$
t_{R}=\frac{R \sqrt{N-K-1}}{1-R^{2}}>2,
$$

where $N$ is the number of described points; $K$ is the number of operating factors.

The calculated values of all partial dependencies and their significance are shown in Table 3.

Having determined the significance of the partial functions, we compiled a generalized Protodyakonov equation for each optimization parameter

$$
Y_{p}=\frac{P_{i=1}^{n} Y_{i}}{Y_{m i d}^{n-1}}
$$

where $Y_{p}$ is the generalized function; $Y_{i}$ is the partial function; $P_{i=1}^{n}$ is the product of all partial functions; $Y_{p}$ is the total average of all values taken into account.

The generalized equation:

$$
Y_{p}=\frac{Y_{1} Y_{2} Y_{3} Y_{4} Y_{5}}{45,8^{4}}
$$

was tested for significance by comparing the calculated results with experimental data. The generalized equation is adequate for all response functions.

Fig. 3 shows the partial dependences of the yield of target products on various factors. 


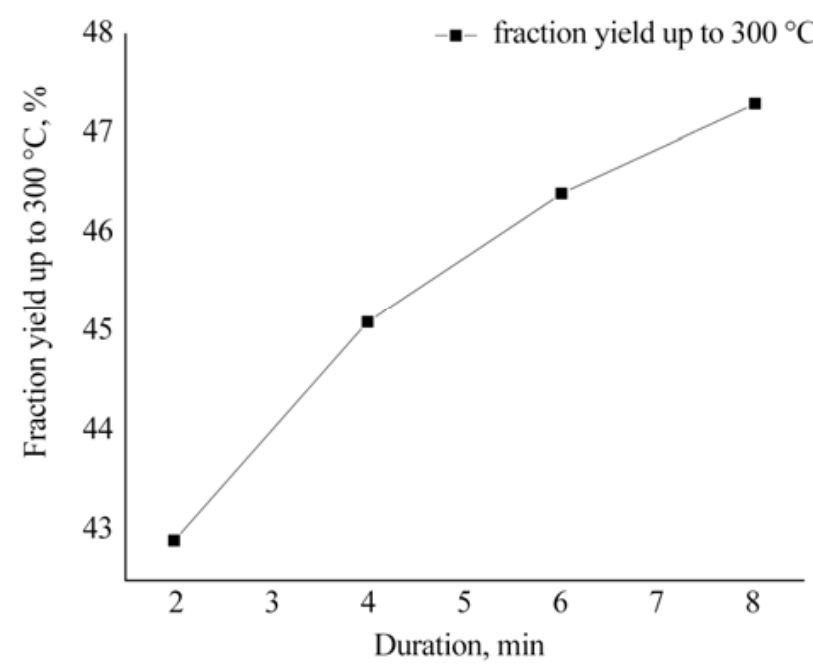

$a$

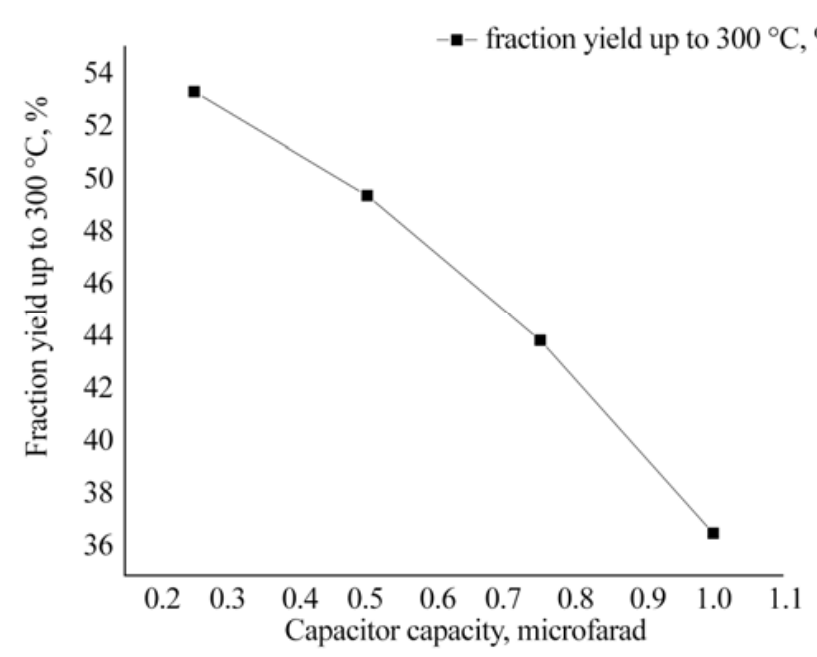

$c$

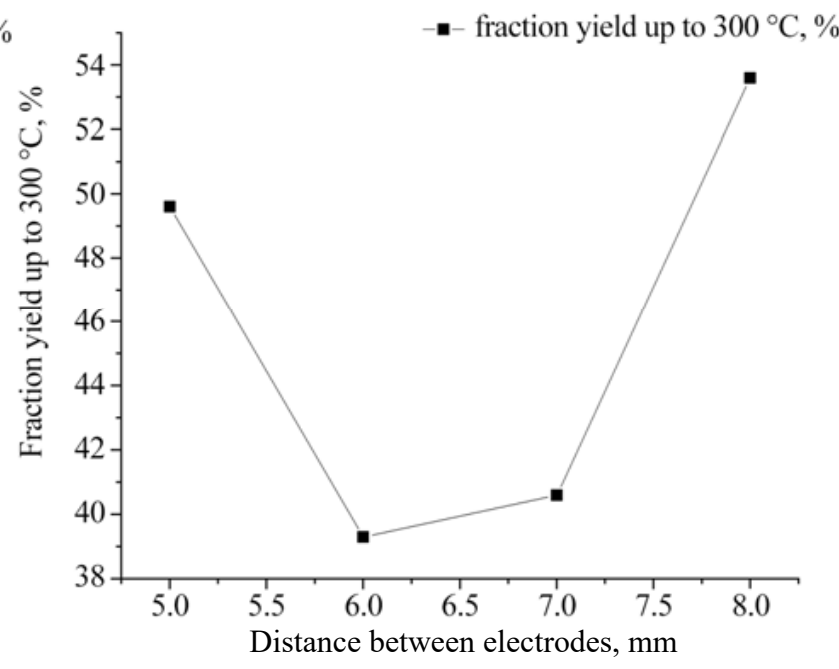

$b$

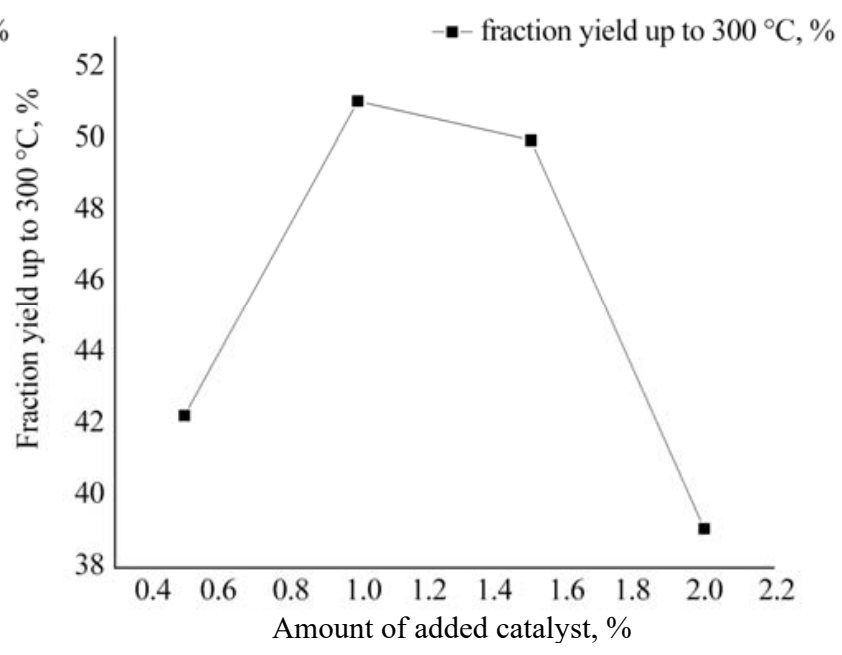

$d$

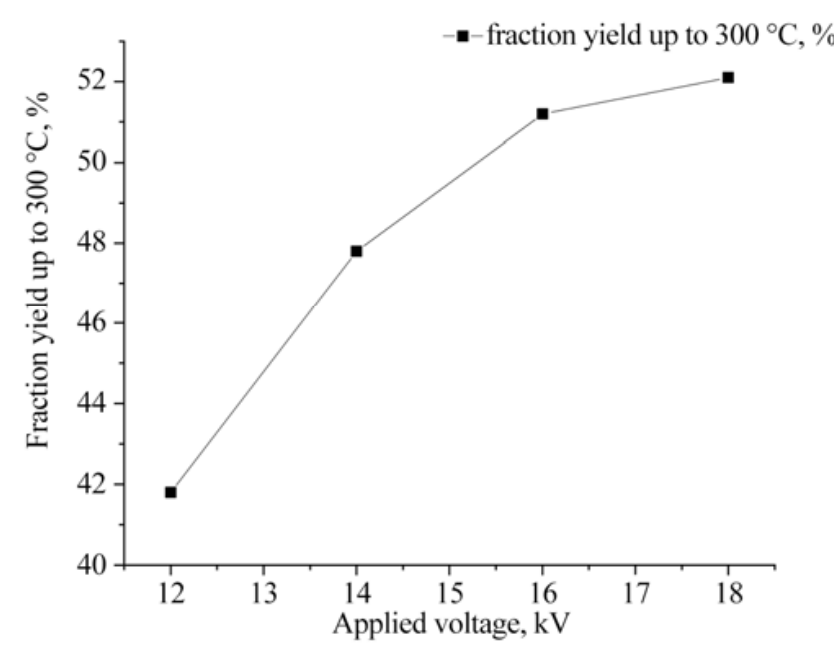

$e$

Fig. 3. Dot plots and curves of approximation to optimize the process of destruction of oil bottom sediments using the electrohydraulic effect: $a$-yield of fraction up to $300{ }^{\circ} \mathrm{C}$ of the duration of treatment; $b-$ yield of fraction up to $300{ }^{\circ} \mathrm{C}$ of the distance between the electrodes; $c$ - yield of fraction up to $300{ }^{\circ} \mathrm{C}$ of the capacitor capacity; $d-$ yield of fraction up to $300{ }^{\circ} \mathrm{C}$ of the amount of added catalyst to the oil bottom sediment; $e$ - yield of fraction up to $300{ }^{\circ} \mathrm{C}$ of the applied voltage 
Matrix of 5-factor planning at four levels

\begin{tabular}{|c|c|c|c|c|c|c|c|}
\hline \multirow{2}{*}{ No. of experiment } & \multicolumn{5}{|c|}{ Factors } & \multirow{2}{*}{$Y_{\text {exp }}$} & \multirow{2}{*}{$Y_{p}$} \\
\hline & $x_{1}$ & $x_{2}$ & $x_{3}$ & $x_{4}$ & $x_{5}$ & & \\
\hline 1 & 1 & 1 & 1 & 1 & 1 & 45.7 & 45.6 \\
\hline 2 & 2 & 2 & 2 & 2 & 1 & 38.4 & 42.6 \\
\hline 3 & 3 & 3 & 3 & 3 & 1 & 41.4 & 39.4 \\
\hline 4 & 4 & 4 & 4 & 4 & 1 & 32.0 & 34.5 \\
\hline 5 & 1 & 2 & 3 & 4 & 2 & 34.5 & 31.4 \\
\hline 6 & 2 & 1 & 4 & 3 & 2 & 47.4 & 44.6 \\
\hline 7 & 3 & 4 & 1 & 2 & 2 & 74.0 & 73.7 \\
\hline 8 & 4 & 3 & 2 & 1 & 2 & 45.3 & 43.6 \\
\hline 9 & 1 & 3 & 4 & 2 & 3 & 36.4 & 38.0 \\
\hline 10 & 2 & 4 & 3 & 1 & 3 & 50.7 & 52.2 \\
\hline 11 & 3 & 1 & 2 & 4 & 3 & 49.0 & 51.7 \\
\hline 12 & 4 & 2 & 1 & 3 & 3 & 55.3 & 57.8 \\
\hline 13 & 1 & 4 & 2 & 3 & 4 & 57.0 & 67.4 \\
\hline 14 & 2 & 3 & 1 & 4 & 4 & 40.3 & 45.2 \\
\hline 15 & 3 & 2 & 4 & 1 & 4 & 27.9 & 32.9 \\
\hline 16 & 4 & 1 & 3 & 2 & 4 & 56.5 & 62.4 \\
\hline
\end{tabular}

Table 2

Levels of the studied factors and intervals of their variation

\begin{tabular}{|c|c|c|c|c|c|}
\hline \multirow{2}{*}{ Factors } & \multirow{2}{*}{$\begin{array}{c}\text { unit of } \\
\text { measure- }\end{array}$} & \multicolumn{5}{|c|}{ Levels } \\
\cline { 4 - 7 } & ment & 1 & 2 & 3 & 4 \\
\hline$X_{1}$, duration & $\mathrm{min}$ & 2 & 4 & 6 & 8 \\
\hline$X_{2}$, distance between electrodes & $\mathrm{mm}$ & 5 & 6 & 7 & 8 \\
\hline$X_{3}$, capacitor capacity & $\mu \mathrm{F}$ & 0.25 & 0.5 & 0.75 & 1 \\
\hline$X_{4}$, amount of added catalyst & $\%$ & 0.5 & 1.0 & 1.5 & 2.0 \\
\hline$X_{5}$, voltage & $\mathrm{kV}$ & 12.0 & 14.0 & 16.0 & 18.0 \\
\hline
\end{tabular}

Calculated values of partial functions for $Y_{P}$

\begin{tabular}{|c|c|c|c|c|c|c|}
\hline \multirow{2}{*}{ Functions } & \multicolumn{4}{|c|}{ Levels } & \multirow{2}{*}{$R$} & $t_{R}$ \\
\cline { 2 - 6 } & 1 & 2 & 3 & 4 & & \\
\hline$Y_{1}=40.93 x_{1}^{0.7}$ & 42.9 & 45.1 & 46.4 & 47.3 & 0.78 & 14,9 \\
\hline$Y_{2}=5.8 x_{2}^{2}-74.08 x+275.02$ & 49.6 & 39.3 & 40.6 & 53.6 & 0.99 & 366,3 \\
\hline$Y_{3}=-13.6 x_{3}^{2}-5.16 x+55.4$ & 53.3 & 49.4 & 43.9 & 36.6 & 0.95 & 71,8 \\
\hline$Y_{4}=-19.9 x_{4}^{2}+47.57 x+23.525$ & 42.3 & 51.2 & 50.1 & 39.1 & 0.99 & 366,3 \\
\hline$Y_{5}=-0.3187 x_{5}^{2}+11.283 x-47.7$ & 41.8 & 47.8 & 51.2 & 52.1 & 0.69 & 9,9 \\
\hline
\end{tabular}

The generalized equation determined the following optimal conditions for the destruction of the oil bottom sediment using electrohydraulic treatment: duration $7 \mathrm{~min}$, distance $8 \mathrm{~mm}$, amount of added catalyst $1.5 \%$, capacitance $0.3 \mu \mathrm{F}$, applied voltage $14 \mathrm{kV}$. According to the significance of the correlation coefficient (Table 3), it should be noted that the dominant factors are the distance between the electrodes and the amount of added catalyst. In [12], it is shown that the optimal treatment for obtaining light fractions from a mixture of oil sludge and diesel fuel is $10 \mathrm{EH}$ shocks. The yield of the light fraction from the oil sludge/diesel fuel mixture (1:1) was $50 \mathrm{ml}$. We believe that the method proposed by the authors of [12] has advantages, but the yield of the light fraction is $50 \%$. Our processing method allows us to obtain a yield of light products up to $300{ }^{\circ} \mathrm{C}$ without the use of light solvents of $51.3 \%$. The advantage is that a relatively high yield of light products from the oil sludge is obtained with a low value of EH impact. However, the addition of gasoline or diesel fuel to the oil sludge does not allow us to calculate the conversion of oil sludge, since we can attribute $50 \mathrm{ml}$ to both diesel fuel and gasoline.

Table 4 shows the results of the individual chemical composition of fractions up to $200{ }^{\circ} \mathrm{C}$ and $200-300{ }^{\circ} \mathrm{C}$ obtained from the oil bottom sediment and from the hydrogenate.

5. 2. Determination of the influence of the electrohydraulic effect in the presence of a catalyst

Table 4 shows the results of the individual chemical composition of fraction up to $200{ }^{\circ} \mathrm{C}$ and $200-300{ }^{\circ} \mathrm{C}$ obtained from the oil bottom sediment and from the hydrogenate.

Table 4

Individual chemical composition of fractions up to $200{ }^{\circ} \mathrm{C}$ and $200-300{ }^{\circ} \mathrm{C}$ obtained from the oil bottom sediment: 1 - fractions obtained from the original oil bottom sediment; 2 - fractions obtained from the hydrogenate

\begin{tabular}{|c|c|c|c|c|}
\hline \multirow[b]{2}{*}{ Component } & \multicolumn{2}{|c|}{1} & \multicolumn{2}{|c|}{2} \\
\hline & $\begin{array}{l}\text { Fraction up to } \\
200^{\circ} \mathrm{C}\end{array}$ & $\begin{array}{l}\text { Fraction up to } \\
200-300{ }^{\circ} \mathrm{C}\end{array}$ & $\begin{array}{l}\text { Fraction up to } \\
200^{\circ} \mathrm{C}\end{array}$ & $\begin{array}{l}\text { Fraction up to } \\
200-300{ }^{\circ} \mathrm{C}\end{array}$ \\
\hline 1 & 2 & 3 & 4 & 5 \\
\hline (Z)-2-Heptene & - & - & 0.30 & - \\
\hline 1-Decanol, 2,2-dimethyl- & 0.36 & - & - & - \\
\hline 1-Ethyl-4-methylcyclohexane & 1.44 & - & - & - \\
\hline 1-Iodo-2-methylundecane 1 & 0.28 & - & - & - \\
\hline 1-Nonyne, 7-methyl- & 0.50 & - & - & - \\
\hline 1-Undecyne & - & - & 0.26 & - \\
\hline 1-Undecene, 4-methyl- & 0.90 & - & - & - \\
\hline 1-Methyl-4-(1-methylethyl)-cyclohe & - & 0.25 & - & - \\
\hline 2- Chloropropionic acid, hexadecyl 1 & - & - & 1.46 & 0.42 \\
\hline 2- Chloropropionic acid, octadecyl 1 & 0.23 & - & - & - \\
\hline 2,4-Heptadienoic acid, 6-methyl-, & - & - & 0.85 & - \\
\hline 2-(6'-Methoxycarbonyl-5'-methyl-2' & - & - & - & 0.34 \\
\hline
\end{tabular}


Continuation of Table 4

\begin{tabular}{|c|c|c|c|c|}
\hline 1 & 2 & 3 & 4 & 5 \\
\hline 3,7,11,15-Tetramethyl-hexadecanol, 1 & - & - & 0.61 & - \\
\hline 3-Methyl-4-(methoxycarbonyl)hexa-2 & - & - & 0.81 & - \\
\hline 3-Chloropropionic acid, heptadecyl 1 & - & - & 0.28 & 0.64 \\
\hline 3-Bromooctane & 2.43 & - & - & - \\
\hline 4-Trifluoroacetoxypentadecane 1 & 0.24 & - & - & - \\
\hline 4-Fluoro-1-ribofuranosylimidazole- 1 & - & 0.19 & - & - \\
\hline 9-Oxabicyclo[3.3.1]nonane-2,6-diol & - & 0.17 & - & - \\
\hline Benzene, (1-methylpropyl)- & 0.26 & 0.21 & 0.59 & - \\
\hline Benzene, 1-methyl-3-propyl- & 0.39 & - & - & - \\
\hline Benzene, 1-methyl-4-propyl- & - & - & 0.28 & - \\
\hline Benzene, 2,4-dimethyl-1-(1-methyle & 0.25 & - & - & - \\
\hline cis-Decalin, 2-syn-methyl- & 0.49 & 0.59 & 0.66 & 0.33 \\
\hline Cyclododecane, ethyl- & - & 0.17 & - & - \\
\hline Cycloheptane, methyl- & - & - & 0.31 & - \\
\hline Cyclohexane, 1,1,3-trimethyl- & 1.80 & - & 0.93 & - \\
\hline Cyclohexane, 1,2,4-trimethyl- & 0.51 & - & - & - \\
\hline Cyclohexane, 1,2,4-trimethyl-, (1. & - & - & 0.38 & - \\
\hline Cyclohexane, 1,2-dimethyl-, trans- & 0.83 & - & 0.38 & - \\
\hline Cyclohexane, 1,3-dimethyl-, trans- & - & - & 1.09 & - \\
\hline Cyclohexane, 1-ethyl-2-methyl-, tr & - & - & 0.42 & - \\
\hline Cyclohexane, 1,3,5-trimethyl-, (1. & 0.92 & - & - & - \\
\hline Cyclohexane, 1,2-dimethyl-3-pentyl & - & 0.24 & - & - \\
\hline Cyclohexane, 1,3-dimethyl-, cis- & 2.14 & - & - & - \\
\hline Cyclohexane, 1,4-dimethyl-, trans- & 0.35 & - & - & - \\
\hline Cyclohexane, 1-ethyl-2-methyl- & 0.27 & - & - & - \\
\hline Cyclohexane, 1-methyl-4-(1-methyle & 1.03 & - & - & - \\
\hline Cyclohexane, 1-methyl-2-propyl- & - & 0.17 & - & - \\
\hline Cyclohexane, 2-butyl-1,1,3-trimeth & 0.25 & 0.36 & - & - \\
\hline Cyclohexane, methyl- & 1.18 & - & 0.73 & - \\
\hline Cyclohexanone, 2-methyl-5-(1-methy & - & - & 0.50 & - \\
\hline Cyclopropane, 1-methyl-2-pentyl- & - & - & 0.58 & - \\
\hline Cyclopentane, 1-pentyl-2-propyl- & 0.21 & 0.38 & - & 0.27 \\
\hline Cyclopentane, hexyl- & - & 0.23 & - & - \\
\hline Decane, 1,1'-oxybis- 1 & 1.23 & 0.51 & 0.67 & 0.16 \\
\hline Decane, 2,6,6-trimethyl- & 5.38 & 0.51 & - & 0.25 \\
\hline Decane, 2,6,7-trimethyl- & 0.69 & - & - & - \\
\hline Decane, 2,6,8-trimethyl- & - & - & 6.64 & - \\
\hline Decane, 2-methyl- & 0.64 & - & 0.53 & 0.17 \\
\hline Decane, 4-methyl- & 0.33 & - & - & - \\
\hline Decane, 3,6-dimethyl- & - & 0.23 & - & - \\
\hline Dodecane, 2,6,10-trimethyl- & - & 0.21 & - & - \\
\hline Dodecane, 2,6,11-trimethyl- & 6.62 & 7.7 & - & 6.21 \\
\hline Dodecane, 2,7,10-trimethyl- & 3.41 & 3.87 & - & 2.53 \\
\hline Dodecane, 2-methyl- & 0.53 & 0.76 & 0.55 & 0.56 \\
\hline Dodecane, 4,6-dimethyl- & - & - & 1.17 & - \\
\hline Dodecane, 2-methyl-8-propyl- & - & 0.67 & - & - \\
\hline Eicosane 1 & 1.12 & 5.54 & 2.41 & 5.36 \\
\hline Fumaric acid, hexadecyl 4-octyl es 2 & - & - & 0.65 & - \\
\hline Heneicosane 1 & - & 4.99 & - & 1.98 \\
\hline Hentriacontane 2 & - & 0.96 & 1.08 & 2.16 \\
\hline Heptacosane 1 & - & - & 1.17 & - \\
\hline Heptadecane & 6.6 & 19.42 & 7.47 & 39.55 \\
\hline Heptadecane, 2-methyl- 1 & - & 0.63 & - & - \\
\hline Heptadecane, 3-methyl- 1 & - & - & - & 0.24 \\
\hline Heptane, 3-ethyl-2-methyl- & 2.2 & 0.57 & - & - \\
\hline Heptane, 4-propyl- & - & 0.28 & - & - \\
\hline
\end{tabular}


Continuation of Table 4

\begin{tabular}{|c|c|c|c|c|}
\hline 1 & 2 & 3 & 4 & 5 \\
\hline Hexadecane, 2,6,10,14-tetramethyl- 1 & 0.37 & 4.12 & 1.32 & 3.42 \\
\hline Hexadecane, 2-methyl- & - & 0.37 & - & 0.49 \\
\hline Hexane, 2,5-dimethyl- & - & - & 0.80 & - \\
\hline Naphthalene, 1,4-dimethyl- & - & 0.66 & - & 0.63 \\
\hline Naphthalene, 1,6-dimethyl- & 0.49 & 0.95 & - & - \\
\hline Naphthalene, 2,3-dimethyl- & - & - & 0.73 & - \\
\hline Naphthalene, 2,6-dimethyl- & - & 0.43 & - & 1.17 \\
\hline Naphthalene, 2,7-dimethyl- & - & - & - & 0.32 \\
\hline Naphthalene, 1-methyl- & 0.61 & 2.59 & 0.58 & 0.94 \\
\hline Naphthalene, 2-methyl- & 0.44 & - & 0.71 & 0.71 \\
\hline Naphthalene, 1,4,6-trimethyl- & - & - & - & 0.25 \\
\hline Naphthalene, 1,6,7-trimethyl- & - & 0.91 & - & 0.65 \\
\hline Nonadecyl trifluoroacetate 1 & - & - & - & 0.56 \\
\hline Nonane, 3-methyl- & 0.64 & - & - & - \\
\hline Nonane, 5-butyl- & 0.57 & 0.31 & 0.43 & - \\
\hline Octacosane 1 & - & 0.78 & 0.44 & - \\
\hline Octadecane, 3-methyl- 1 & - & 0.22 & - & 0.28 \\
\hline Octadecane, 6-methyl- 1 & - & - & 0.53 & - \\
\hline Octane, 2,3,6-trimethyl- & 0.56 & - & - & - \\
\hline Octane, 2,3,7-trimethyl- & - & - & 0.51 & - \\
\hline Octane, 2,3-dimethyl- & 0.81 & - & 0.78 & - \\
\hline Octane, 2,6-dimethyl- & 1.52 & 0.42 & 2.62 & 0.28 \\
\hline Octane, 3,5-dimethyl- & 0.82 & - & - & - \\
\hline Octane, 3-methyl- & 1.62 & - & 1.01 & - \\
\hline Octane, 2-iodo- & - & - & 0.34 & - \\
\hline Oxalic acid, cyclobutyl pentadecyl 1 & 0.18 & & & - \\
\hline Oxalic acid, cyclobutyl hexadecyl 1 & - & 0.16 & - & - \\
\hline Oxalic acid, cyclohexylmethyl isoh 1 & 0.30 & - & - & - \\
\hline Oxalic acid, 2-ethylhexyl octyl es 1 & - & - & 0.28 & - \\
\hline Pentadecane & 8.56 & - & - & - \\
\hline Pentadecane, 2,6,10,14-tetramethyl 1 & 0.65 & 2.38 & 0.95 & 2.97 \\
\hline Pentadecane, 2,6,10-trimethyl- 1 & 0.58 & 8.04 & 17.45 & 1.78 \\
\hline Pentadecane, 3-methyl- & - & 0.31 & - & 0.33 \\
\hline o-Xylene & - & - & 1.36 & - \\
\hline p-Xylene & 1.85 & 0.17 & - & - \\
\hline Sulfurous acid, butyl heptadecyl e 1 & 0.75 & 1.24 & - & 1.12 \\
\hline Sulfurous acid, di(2-ethylhexyl) e 1 & 2.10 & - & - & - \\
\hline Sulfurous acid, 2-ethylhexyl undec 1 & - & - & 2.7 & - \\
\hline Tetracontane, 3,5,24-trimethyl- 2 & - & 1.29 & - & - \\
\hline Tetradecane, 3-methyl- & 0.39 & 1.20 & - & 1.11 \\
\hline Tetracosane 1 & - & 1.85 & - & 3.10 \\
\hline Tetrapentacontane, 1,54-dibromo- 2 & - & - & - & 0.72 \\
\hline $\begin{array}{l}\text { Toluene } \\
\end{array}$ & 1.25 & - & 1.15 & - \\
\hline trans-Decalin, 2-methyl- & 0.74 & 0.49 & - & 0.38 \\
\hline Tridecane, 6-methyl- & - & 0.49 & - & 0.39 \\
\hline Tridecane, 7-methyl- & - & 2.89 & 0.28 & - \\
\hline Undecane, 2,5-dimethyl- & - & - & 1.79 & - \\
\hline Undecane, 2,6-dimethyl- & 1.73 & 1.73 & 0.58 & 1.28 \\
\hline Undecane, 3,5-dimethyl- & 7.50 & - & - & - \\
\hline Undecane, 3,6-dimethyl- & 4.85 & 2.31 & - & 1.18 \\
\hline Undecane, 3-ethyl- & 0.25 & - & - & - \\
\hline Undecane, 4,8-dimethyl- & 0.21 & - & - & - \\
\hline Undecane, 6,6-dimethyl- & 1.49 & 0.46 & 6.84 & 0.25 \\
\hline Undecane, 6-methyl- & - & - & - & 0.35 \\
\hline Undecane, 6-ethyl- & 0.96 & 0.28 & - & - \\
\hline
\end{tabular}

Note: 2 - fractions up to $200^{\circ} \mathrm{C}$ and $200-300^{\circ} \mathrm{C}$ obtained from the hydrogenated product under the following conditions of oil bottom sediment processing using the electrohydraulic effect: duration - 2 min, distance between electrodes $-8 \mathrm{~mm}$, capacitor capacity - $0.5 \mu \mathrm{F}$, amount of catalyst $-1.5 \%$, voltage $-22 \mathrm{kV}$. 
1,1,3-trimethyl-cyclohexane decreases from $1.8 \%$ to $0.93 \%$. Paraffinic hydrocarbons decrease from $5.89 \%$ to $0.25 \%$. Polyaromatic hydrocarbons decreases from $3.2 \%$ to $1.52 \%$. The obtained results allow us to conclude that the electrohydraulic effect is effective for the destruction of the organic mass of the oil bottom sediment.

The obtained light and middle fractions from oil sludge can be used as additives to gasoline to increase the octane number and to diesel fuel to increase the cetane number. Fractions above $300^{\circ} \mathrm{C}$ can be used to obtain petroleum bitumen (road asphalt).

\section{Discussion of the results obtained in determining the optimal conditions of oil sludge processing using the electrohydraulic effect}

When planning a full factorial experiment (Tables 1, 2), all possible combinations of factors are implemented at all levels selected for the study. The number of experiments is 16 (Table 1). Experiments were conducted on 4 levels. The influence of 5 factors on the yield of the light and medium fractions was studied: the duration of the electrohydraulic impact, the distance between the electrodes, the capacitance of the capacitor, the amount of catalyst added, voltage. To check the adequacy of dependencies (Table 3), the nonlinear multiple correlation coefficient (1) was used. The purpose of this coefficient $R$ is to determine the degree of difference between the data spread relative to some theoretical dependence and a relatively insignificant dependence expressed by a single average value (Table 3 , Fig. 3 ). The significance of the correlation coefficient $t_{R}$, and hence the tested dependencies for $95 \%$ of the confidence level was determined by the inequality (2).

The significance of the correlation coefficient $t_{R}$ (Table 3 , Fig. 3) showed that the dominant factors in the process of oil sludge processing are the distance between the electrodes and the amount of catalyst added. The matrix of the full factorial experiment used (Table 1) does not require duplication of the experiment.

The obtained results of individual and group chemical composition of light and medium fractions (Table 4) showed that they can be used not only as additives to increase the octane and cetane number of gasoline and diesel fuel, but also as raw materials for reforming and for obtaining rocket fuel. Since the middle fraction contains a large amount of monocyclic and bicyclic aromatic hydrocarbons. As is known, aromatic hydrocarbons have high densities and calorific values. The individual and group chemical composition presented in Table 4 showed that the light fraction is represented by a mixture of branched alkanes and cycloalkanes, as well as the insignificant presence of sulfur, oxygen and nitrogen compounds, which does not require the use of the hydrotreatment process.

The advantage of this study is that the mathematical model (4), due to its physical determinism, can also be used to open the internal connection of the oil sludge processing process, for example, for kinetic analysis.

The determined individual chemical composition of the light fractions obtained from the oil sludge hydrogenate made it possible to give recommendations on the practical use of these fractions to improve the operational properties of gasoline, diesel fuel and jet fuel.

The method of mathematical planning of the experiment is limited by the intervals of the studied factors. The disadvantages of our research is that we have not studied the effect of the mechanism of destruction of the organic mass of oil sludge using model organic objects (phenanthrene, benzothiophene and benzofuran). We were unable to investigate the group and individual chemical composition of the fractions above $300{ }^{\circ} \mathrm{C}$. We believe that our further research will be directed to solving these tasks set out above.

\section{Conclusions}

1. The optimal conditions for processing oil bottom sediments using the electrohydraulic effect have been determined: duration $7 \mathrm{~min}$, distance $8 \mathrm{~mm}$, amount of added catalyst $1.5 \%$, capacitance $0.3 \mu \mathrm{F}$, applied voltage $14 \mathrm{kV}$.

2 . It was found that the light and middle fractions obtained from the hydrogenated product consist mainly of saturated and polyaromatic compounds. Alkanes are represented by the homolytic series $\mathrm{C}_{7}-\mathrm{C}_{11}$, monoaromatic hydrocarbons are alkyl derivatives of benzene, cycloalkanes are alkyl derivatives of cyclohexane, and bicyclic hydrocarbons are alkyl derivatives of naphthalene.

\section{Acknowledgments}

The work was carried out within the framework of the AP09563282 grant of the Ministry of Education and Science of the Republic of Kazakhstan.

\section{References}

1. Kovalevskiy, V. F., Skobelev, S. B. (2018). Experimental studies of electrohydraulic effect application of L. A. Yutkin for removal of flares from terminals of plastic details. Omsk Scientific Bulletin, 6 (162), 174-177. doi: https://doi.org/10.25206/1813-8225-2018162-174-177

2. Kusaiynov, K. (2016). Elektrogidroimpul'snaya tekhnologiya ochistki trub i puchkov trub teploobmennikov. Karaganda: Izd-vo KarGU, 240 .

3. Loskutova, Yu. V., Yudina, N. V., Prozorova, I. V. (2021). Fiziko-himicheskaya obrabotka neftyanyh osadkov pri utilizatsii nefteshlamov. Himiya tverdogo topliva, 4, 66-72. doi: https://doi.org/10.31857/s0023117721040046

4. Gopang, I. A., Mahar, H., Jatoi, A. S., Akhtar, K. S., Omer, M., Azeem, M. S. (2016). Characterization of the sludge deposits in crude oil storage tanks. Journal of Faculty of Engineering \& Technology, 23 (1), 57-64.

5. Butov, V. G., Nikulchikov, A. V., Nikulchikov, V. K., Solonenko, V. A., Yashchuk, A. A. (2018). Simulation study of bottom sediments jet erosion in oil tank. Bulletin of the Tomsk Polytechnic University. Geo Assets Engineering, 329 (9), 93-100. Available at: http:// earchive.tpu.ru/bitstream/11683/51016/1/bulletin_tpu-2018-v329-i9-09.pdf 
6. Xiao, W., Yao, X., Zhang, F. (2019). Recycling of Oily Sludge as a Roadbed Material Utilizing Phosphogypsum-Based Cementitious Materials. Advances in Civil Engineering, 2019, 1-10. doi: https://doi.org/10.1155/2019/6280715

7. Mater, L., Sperb, R., Madureira, L., Rosin, A., Correa, A., Radetski, C. (2006). Proposal of a sequential treatment methodology for the safe reuse of oil sludge-contaminated soil. Journal of Hazardous Materials, 136 (3), 967-971. doi: https://doi.org/10.1016/ j.jhazmat.2006.01.041

8. Hui, K., Tang, J., Lu, H., Xi, B., Qu, C., Li, J. (2020). Status and prospect of oil recovery from oily sludge: A review. Arabian Journal of Chemistry, 13 (8), 6523-6543. doi: https://doi.org/10.1016/j.arabjc.2020.06.009

9. Monteiro, M., Svet, V., Sandilands, D., Tsysar, S. (2015). Experimental Investigations of Various Methods of Sludge Measurements in Storage Oil Tanks. Advances in Remote Sensing, 04 (02), 119-137. doi: https://doi.org/10.4236/ars.2015.42011

10. Musina, U. Sh., Vasichkin, A. S. (2014). Obzor sposobov utilizatsii nefteothodov i tekhnologiy ih utilizatsii. Vestnik KazGASA, 2 (52), 133-141. Available at: http://rmebrk.kz/journals/1536/90808.pdf\#page=134

11. Galiullin, E. A., Fakhrutdinov, R. Z., Djimasbe, R. (2016). Obezvozhivanie nefteshlamov termomekhanicheskim metodom. Vestnik tekhnologicheskogo universiteta, 19 (4), 55-57.

12. Bodykov, D. U., Abdikarimov, M. S., Seitzhanova, M. A., Elemessova, Zh. K. (2017). Recycling of oil sludge using electrohydraulic effect. Gorenie i plazmohimiya, 15 (2), 140-147. Available at: http://cpc.icp.kz/index.php/cpc/article/view/74/70

13. Bodykov, D. U., Abdikarimov, M. S., Mansurov, Z. A. (2015). Recycling of oil sludge using electrohydraulic effect Yutkina. Gorenie i plazmohimiya, 13 (4), 303-311. Available at: http://cpc.icp.kz/index.php/cpc/article/view/32/32

14. Bodykov, D. U., Abdikarimov, M. S., Mansurov, Z. A. (2016). Sludge processing using electrohydraulic effect. World Conference on Carbon (Carbon 2016), 541

15. Malyshev, V. P., Katkeeva, G. L., Zubrina, Yu. S., Oskembekov, I. M., Gizatullina, D. R. (2017). Development of integrated probabilistic and deterministic models for grinding and flotation processes. Kompleksnoe ispol'zovanie mineral'nogo syr'ya, 1, 47-53. Available at: https://www.elibrary.ru/item.asp?id=36930262 